https://doi.org/10.7203/Celestinesca.33.20083

\title{
In memoriam, Alan Deyermond
}

Alan Deyermond, querido maestro y amigo, el más destacado miembro del consejo editorial de Celestinesca, falleció el 19 de septiembre de 2009, dejándonos el corazón sumido en una profunda congoja también a los miembros del consejo de redacción.

Con estas líneas no queremos más que sumarnos, desde la redacción de nuestra revista, al elogio unánime de hispanistas y medievalistas de todo el mundo a un gran profesional de las letras, de la investigación y de la educación, que rindió durante más de cincuenta años un impagable servicio a las humanidades, a la crítica filológica y a la historia de la literaturas peninsulares, y que demostró infatigablemente su compromiso con el conocimiento y con la ciencia.

Es obligado destacar desde estas páginas la dedicación de Alan Deyermond a La Celestina, que fue temprana, duradera, profunda. En su primer artículo, "The Index to Petrarch's Latin Works as a Source of La Celestina», escrito antes de doctorarse y publicado en el número 31 (1954) del Bulletin of Hispanic Studies, demostraba que el índice temático de las obras latinas de Petrarca, al final de la primera edición incunable, salida en Basilea, en 1496, había sido la principal fuente petrarquesca de Rojas. Ese índice de las Opera de Petrarca sirvió de florilegio a Fernando de Rojas, que no se tomaba la molestia de averiguar si las sentencias anotadas coincidían o no con las fuentes originales; lo que no quiere decir que a veces Rojas no consultara directamente determinadas obras del italiano, y desde luego el De remediis utrisque fortunae. Este artículo fue el precoz avance de su estudio sobre las fuentes petrasquescas de La Celestina: The Petrarchan Sources of "La Celestina" (Londres, Oxford University Press, 1961; reed. revisada, 1975). En el libro, se parte de la constatación de que Petrarca es el autor más citado por Fernando de Rojas: en alrededor de cien ocasiones (unas setenta y cinco en la Comedia, otras veinticinco en los nuevos actos e interpolaciones).

Pero, por supuesto, la Celestina continuó interesando al prof. Deyermond, con pluralidad de enfoques. El primero, "The Text-Book Mishan- 
dled: Andreas Capellanus and the Opening Scene of La Celestina» (Neophilologus, 45, 1961, pp. 218-21). Seguirían: «La crítica de La Celestina de Jacques de Lavardin» (Hispanófila, 13 (1961), 1-4); «Hilado-Cordón-Cadena: Symbolic Equivalence in La Celestina» (Celestinesca, 1-ii, 1977, pp. 6-12), que, como recuerda Joseph Snow en estas páginas, ha sido uno de los más citados de entre todos los publicados en Celestinesca a lo largo treinta años; "Symbolic Equivalence in La Celestina: A Postscript» (Celestinesca, 2.1, 1978, pp. 25-30); “'Muerto soy! ¡Confesión!’: Celestina y el arrepentimiento a última hora» (en De los romances-villancico a la poesía de Claudio Rodríguez: 22 ensayos sobre las literaturas española e hispanoamericana en homenaje a Gustav Siebenmann, ed. José Manuel López de Abiada y Augusta López Bernasocchi, Madrid, José Esteban, 1984, 129-40), "Divisiones socio-económicas, nexos sexuales: la sociedad de Celestina» (Celestinesca, 8-ii [In Honor of Stephen Gilman, ed. Dorothy Sherman Severin], 1984, pp. 3-10); «'El que quiere comer el ave': Melibea como artículo de consumo" (en Estudios románicos dedicados al profesor Andrés Soria Ortega en el XXV aniversario de la Cátedra de Literaturas Románicas, ed. Jesús Montoya Martínez y Juan Paredes Núñez, I, Granada, Universidad, 1985, pp. 291300); "Pleberio's Lost Investment: The Wordly Perspective of Celestina, Act 21" (Modern Language Notes, 105, 1990, pp. 169-79); "Female Societies in Celestina" (en Fernando de Rojas and "Celestina»: Approaching the Fifth Centenary [Proceedings of an International Conference in Commemoration of the 450 th Anniversary of the Death of Fernando de Rojas, Purdue University, West Lafayette, Indiana, 21-24 November 1991], ed. Ivy A. Corfis y Jopeph Snow, Madison, HSMS, 1993, pp. 1-31); "Hacia una lectura feminista de la Celestina» (en "La Célestine»: "Comedia o Tragicomedia de Calisto y Melibea» [Actes du Colloque International du 29-30 janvier 1993], ed. Françoise Maurizi, Caen, Universidad, 1995, pp. 59-86); "La Celestina como cancionero» (en Cinco Siglos de "Celestina": aportaciones interpretativas, ed. Rafael Beltrán y José Luis Canet, Valencia, Universidad, 1997, pp. 91-105); «How Many Sisters Had Celestina? The Functions of the Invisible Characters» (Celestinesca, 21, i-ii [Studies in Honour of Louise Fothergill-Payne], 1997, pp. 15-29); "Motivación sencilla y motivación doble en La Celestina», (Insula, 663, 2000, 13-15); "Readers in, Readers of, Celestina» (en Context, Meaning and Reception of "Celestina". A Fifth Centenary Symposium = Bulletin of Hispanic Studies (Glasgow) , 78, 1, 2001, 13-37); "Abstracción mítica y actualidad localizada en la Celestina" (en "Celestina". La comedia de Calisto y Melibea, ed. Gonzalo Santonja, Madrid, España Nuevo Milenio, 2001, pp. 59-70).

La revista Celestinesca le debe mucho a Alan Deyermond y, en su nueva etapa valenciana, ha continuado en deuda con su persona. Como recuerda Joseph Snow, en las páginas de este número, su opinión fue decisiva y crucial su intervención a la hora de decidir el "traspaso de poderes» y de universidad editora. Él demostró siempre una especial atención, profesional y personal, hacia cada uno de los miembros del grupo valenciano de 
medievalistas, formado por la mitad del consejo de redacción y el propio editor de la revista. Y ese "círculo valenciano» intentó demostrarle, en justa reciprocidad, su humilde y rendido agradecimiento, solicitando y logrando que la Universitat de València le concediera el mayor galardón que se le puede otorgar a un académico, el Doctorado Honoris Causa.

Alan Deyermond expandió por doquier, como sólo los grandes maestros pueden hacer, con generosidad inagotable, su caudal de saberes y experiencias, dejando una huella imborrable en filólogos e historiadores de la cultura y de la literatura.

Un homenaje como el que le queremos hacer, desde este número de la revista, queda muy corto para compensar sus méritos, pero sabemos que le habría complacido.

Que descanses en paz, Alan. Diste siempre a los demás lo mejor de ti y te mereces el cielo de los mejores.

El Editor, Consejo de Redacción y Consejo Editorial 
